\title{
The Processing of Grammatical Gender Agreement in Brazilian Portuguese: ERP Evidence in Favor of a Single Route
}

\author{
Natália Carolina Alencar de Resende ${ }^{1}$ (D) $\cdot$ Mailce Borges Mota ${ }^{2}$ (D) $\cdot$ Pieter Seuren $^{3}$
}

Published online: 16 August 2018

(c) Springer Science+Business Media, LLC, part of Springer Nature 2018

\begin{abstract}
The present study used event-related potentials to investigate whether the processing of grammatical gender agreement involving gender regular and irregular forms recruit the same or distinct neurocognitive mechanisms and whether different grammatical gender agreement conditions elicit the same or diverse ERP signals. Native speakers of Brazilian Portuguese read sentences containing congruent and incongruent grammatical gender agreement between a determiner and a regular or an irregular form (condition 1) and between a regular or an irregular form and an adjective (condition 2). However, in condition 2, trials with incongruent regular forms elicited more positive ongoing waveforms than trial with incongruent irregular forms. We found a biphasic LAN/P600 effect for gender agreement violation involving regular and irregular forms in both conditions. Our findings suggest that gender agreement between determiner and nouns recruits the same neurocognitive mechanisms regardless of the nouns' form and that, depending on the grammatical class of the words involved in gender agreement, differences in ERP signals can emerge.
\end{abstract}

Keywords Gender agreement · Regular and irregular forms · Brazilian Portuguese · Event-related potentials

\section{Introduction}

In many of the world's languages, all nouns, including those designating inanimate entities, are distributed into gender categories (e.g., Corbett 1991). For instance, in romance languages (such as Spanish, French, Portuguese, and Italian), nouns designating animate beings, such as 'girl', 'boy', as well as nouns designating inanimate referents such as 'house', 'culture' and 'car' can be categorized as feminine or masculine nouns. Thus, in these languages,

Mailce Borges Mota

mailce.mota@ufsc.br

1 ADAPT Centre, School of Computing, Dublin City University, Dublin, Ireland

2 Department of Foreign Languages and Literatures, Federal University of Santa Catarina (UFSC), Florianópolis, SC, Brazil

3 Max Planck Institute for Psycholinguistics, P.O. Box 310, 6500 AH Nijmegen, The Netherlands 
the so-called 'Natural Gender' or 'Semantic Gender' is assigned to nouns denoting 'male' or 'female' beings and refers to a semantic property, the biological sex of the referent. Grammatical gender, on the other hand, is a formal property assigned to nouns of inanimate referents.

Both natural and grammatical gender of nouns play a crucial role at the syntactic level. Natural and grammatical gender are manifest in the selection of the article and in other nominal agreement features such as adjectives and participial forms. Hence, for adequate and fluent language use, speakers of romance languages must learn either the semantic or the grammatical gender of every noun to perform noun phrase gender agreement properly. In fact, native speakers of romance languages seem to make very few or no gender agreement mistakes (Pérez Pereira 1991; Seigneuric et al. 2007). Given this high level performance in gender agreement, researchers (e.g., Gollan and Frost 2001; Hohfeld 2006; Taft and Meunier 1998; Tucker et al. 1968) have asked how native speakers 'know' the gender of many inanimate nouns since this information cannot be based on a semantic property.

A possibility would be the presence of phonological cues in the phonological structure of many nouns for gender assignment (Tucker et al. 1968). For example, Spanish has the endings of the nouns as a phonological cue for gender assignment: inanimate nouns ending in $-a$ tend to be feminine, whereas nouns ending in $-o$ tend to be masculine (Barber et al. 2004). However, in Spanish, as in other romance languages, the relationship between word form and grammatical gender is far from being a consistent rule, since nouns ending in other phonemes may be of either gender. Thus, how native speakers process gender agreement regardless of the arbitrary relation between form and grammatical gender has been a matter of debate within the field of psycholinguistics over the past decades (Bates and Devescovi 1989; Bates et al. 1995, 1996; Clark 1985; Matthews 2010; Rodina 2007). The discussion is centered around the issue of one or two routes for the processing of grammatical gender.

One group of researchers (e.g., Levelt et al. 1999; Jescheniak and Levelt 1994; Roelofs 1992) claims that there is a single route for the processing of grammatical gender. According to this view, since grammatical gender does not refer to a semantic property, it represents abstract information extracted via lexical activation. Grammatical gender information is stored in the mental lexicon as part of the description of each noun. In other words, proponents of this view assume that all nouns belonging to a grammatical gender category are linked to one gender node, i.e., there is only one abstract node for each grammatical gender category so that speakers do not need to specify each noun's grammatical gender separately. Another group of researchers (Gollan and Frost 2001; Tucker et al. 1968) posits that there are two routes for the processing of grammatical gender. Under this perspective, besides the lexically-based route, a distinct computational route is necessary to account for gender regular nouns since speakers rely on cues present in the phonological structure of nouns to perform gender agreement and gender assignment properly. This latter view is based on a number of behavioral studies (e.g., Afonso et al. 2014; Desrochers et al. 1989; Gollan and Frost 2001; Hohfeld 2006; Taft and Meunier 1998) showing effects of gender regularities, i.e., faster reaction times and higher accuracy in gender decision to gender regular nouns (feminine nouns ending in - $a$ and masculine nouns ending in -o) as compared to nouns with other endings (Afonso et al. 2014, p. 15). Moreover, some fMRI studies have shown greater activation in Broadmann's area BA45 for the processing of grammatical gender of opaque forms than for regular/transparent forms (Hernandez et al. 2004, 2007; Padovanni et al. 2005), suggesting different processing routes.

Although cross-linguistic regularity effects on the processing of grammatical gender have been consistently observed in behavioral and fMRI studies, some studies have shown frequency effects - that is, high frequency items elicit faster reaction times than low frequency items because they are seen more often. Consequently, high frequency items are more readily 
recognized and more easily retrieved from the lexicon than low frequency items. Thus, if both regular and irregular forms elicit frequency effects, then the data suggest that long-term memory, i.e., the lexicon, plays a central role in the processing of grammatical gender regardless of the form of the nouns. Desrochers et al. (1989) and Taft and Meunier (1998), for instance, observed an independent frequency effect influencing the processing of grammatical gender in French. This pattern of results suggests that, in order to assign gender, French speakers retrieve nouns from memory regardless of their forms. Similarly, Dominguez et al. (1999) reported frequency effects in the processing of gender in Spanish, suggesting that gender is stored in the mental lexicon as part of the lemma information of each noun.

Thus, the contradictory results encountered in the literature clearly indicate that the processing and representation of grammatical gender is still an open question. If results of some studies suggest that gender can be computed on the fly based on the information present in the words' phonological structure, how to explain frequency effects for gender regular/transparent forms?

A reasonable explanation to the finding that regular forms can elicit frequency effects is provided by Bybee's model (1995) of morphological processing and by connectionist models. According to these models, effects of regularity do not mean activation of a computational route, but instead reflect the strength of the connections of certain structural patterns. Hence, if certain structural patterns are more frequent than others, the strength of the connections of frequent patterns is greater than the strength of the connections of infrequent ones. That is, the higher the frequency of occurrence of a certain pattern, the higher the strength of the connections of this pattern. Bybee (1995) claims that, behaviorally, the superior strength of certain connections would be manifested as faster reaction times and higher accuracy. In this sense, all forms would be retrieved from and processed by a single connectionist/associative memory mechanism (thus revealing frequency effects), but differences in reaction time and accuracy would be related to differences in strength of (morpho)phonological patterns. Thus, those models explain regularity effects on the basis of strength of structural patterns and frequency effects as the manifestation of lexical access.

Here, we address the debate between single versus dual route accounts of grammatical gender processing by exploring data from Brazilian Portuguese, a language that has received little attention from psycholinguists, but that can contribute further evidence to constrain models of grammatical gender processing.

Portuguese, like other romance languages, presents a hybrid gender system: semantic and grammatical gender (Corrêa and Name 2003). In Portuguese, both animate and inanimate nouns ending in $-a$ tend to be feminine (e.g. casa "house ${ }_{F E M}$ ", menina "girl ${ }_{\text {FEM", }}$ cultura "culture $\mathrm{FEM}$ "). Animate and inanimate nouns ending in -o tend to be masculine (e.g. carro "car MASC", garoto "boyMASC", pensamento "thought MASC"). Other endings are also typical of one grammatical gender category. For example, inanimate nouns ending in -ade and -agem

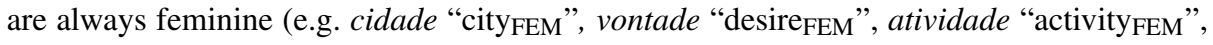
imagem "image FEM", coragem "courage $_{\mathrm{FEM}}$ "); nouns ending in -ema are always masculine (e.g., cinema "cinema MASC", problema "problem MASC", edema "edemaMASC"), as are nouns ending in -or (e.g., amor "love MASC", calor "heat MASC"), except for 3 monosyllabic nouns (flor "flower FEM", cor "color $F E M$ ", dor "pain FEM"), which are feminine. However, there are

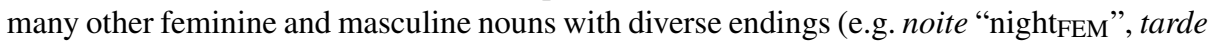
"afternoon FEM", mulher "woman $_{\text {FEM", homem "man }}$ MASC") and a few nouns that present the reverse pattern, that is, a few masculine nouns ending in - a (e.g. poeta "poet MASC",

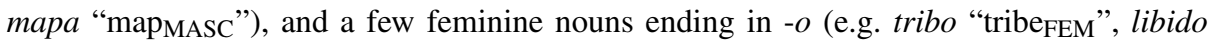
"libidoFEM"). 
It is important to note that, in Portuguese, feminine nouns ending in - $a$, and masculine nouns ending in $-o$ are considered gender regular nouns. Nouns presenting the reverse pattern are considered gender irregular nouns. Nouns whose gender can be recovered from their surface form (such as nouns ending in -ade and -ema) are considered phonologically transparent nouns. Nouns whose gender cannot be recovered from their surface forms (e.g., árvore "tree FEM", réptil "reptile $_{\text {FEM") }}$ are considered phonologically opaque nouns. In the present study, for reasons of economy, we refer to all feminine nouns whose endings are not $-a$ and all masculine nouns whose endings are not $-o$ as gender irregular forms.

In Portuguese, as in Spanish, inanimate nouns ending in - $a$ and $-o$ are far more frequent than gender transparent, irregular, and opaque nouns. The feminine ending $-a$ and the masculine ending $-o$ can be affixes attached to adjectives (bonit-o $o_{\mathrm{MASC}}$, bonit- $a_{\mathrm{FEM}}$ "beautiful"), to

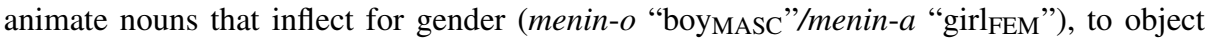

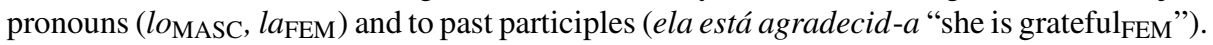
The vowel $a$ can also function as the feminine definite article and $o$ as the masculine definite article preceding feminine and masculine nouns. Thus, the superior frequency of vowels $-a$ and - $o$ as compared to other endings as well as the different roles these phonemes can play may have led to a 'proceduralization' of $-a$ and $-o$. Evidence for this 'proceduralization' was shown by Afonso et al. (2014) for Spanish. In the study, researchers contrasted the size of the regularity effect between gender regular nouns (feminine nouns ending in $-a$ and masculine nouns ending in -o) and nouns with gender-correlated-word-endings such as - $a d$ (e.g. ciudad). Regularity effects were found only for - $a$ and -o, suggesting that regular forms are processed by a mechanism distinct from the mechanism responsible by other forms. Thus, it is possible to assume that, in Portuguese, a language that is similar to Spanish in many respects (Jensen 1989), gender agreement involving regular nouns is computed, while gender agreement involving irregular forms must require lexical access.

To test this hypothesis, we carried out an electrophysiological study using a violation paradigm that aimed at investigating whether, during sentence comprehension in Portuguese, gender agreement processing involving gender regular inanimate forms and gender agreement processing involving other gender forms (feminine nouns whose endings are different from $-a$, and masculine nouns whose endings are different from -o) elicit the same or different ERP responses indexing the same or distinct neurocognitive mechanisms.

It is noteworthy that the EEG approach using a violation paradigm has been widely adopted as an optimal method to investigate the processing routes of regular versus irregular morphology in different languages. Newman et al. (2007), for instance, studied the processing routes of regular versus irregular verbs in English. Subjects read congruent and incongruent sentences in four conditions: regular past tense, irregular past tense, phrase structure and lexical semantics. Results revealed a LAN for the processing of sentences containing violations in regular verbs only, and a P600 for both regular and irregular verbs in English. The authors interpreted different ERP responses indexing the processing of regular and irregular verbs as evidence in favor of the dual-mechanism view.

Weyerts et al. (1997) investigated whether the application of irregular affixes to regularly inflected noun plural forms and regular affixes to irregularly inflected noun plural forms in German elicit different or the same ERPs. Results showed different components to regular and irregular plurals: irregular plurals incorrectly inflected elicited a left frontotemporal negativity. The incorrect regulars produced a central phasic negativity with a maximum at $380 \mathrm{~ms}$. Based on the results, the researchers supported the view that regularly inflected words are processed differently from irregularly inflected ones.

Rodriguez-Fornells et al. (2001) investigated regular and irregular verbal inflection in Catalan using a violation paradigm. Participants read short stories containing correct and 
incorrect forms of regular and irregular past participles. There were two violation conditions: Stem violations and Inflectional violations. Stem violations were created replacing the correct theme vowel for an incorrect one (for example, replacing theme vowel - $a$ of the first conjugation for $-i$ of the third conjugation), but maintaining the correct inflectional suffix $-t$. Inflectional violation was created only for the irregular past participles by using the root followed by the theme vowel of the first conjugation and the regular - $t$ participle. In the study, the violation of the stem formation rule elicited an early left negativity, while violations of the participle inflectional rule did not. The authors interpreted these results as evidence for distinct systems for rule-based and memory-based processes.

Various studies have investigated the processing of grammatical gender agreement in language comprehension by means of event-related potentials (ERPs). Molinaro et al. (2011), in their review of the ERP literature on agreement processing during sentence comprehension, show that, despite the differences in gender patterns across languages, the majority of studies reported a biphasic LAN/P600 effect for gender agreement violations, which is taken as evidence for rule-based computations in gender processing. In their view, the LAN (leftanterior negativity) reflects a violation of expectancy for morphophonological processing, whereas the late positivity reflects integration processes at the sentence level. In fact, the P600 has been reported in studies on gender agreement mismatches involving determiner-noun and noun-adjective, in various languages, and has been associated with reanalysis and repair, nonsyntactic late integration processes, as well as processes involved in structure building, checking, and reprocessing, whereas LAN effects have been more commonly found in studies of gender agreement violations within the determiner-noun phrase in Romance languages and have been associated with automatic perception of grammatical violations, difficulties in the processing of violations, and working memory overload (Caffarra et al. 2015).

In the current study, we examined two gender agreement conditions: between a determiner and a noun (condition 1), and between a noun and an adjective (condition 2) in order to investigate if ERPs elicited to violations in gender agreement with gender regular nouns are different from the ERPs elicited to nouns with other endings in the two conditions. Contrasting agreement conditions will help us to determine if the same pattern holds when different word classes and syntactic structures are involved in gender agreement.

The rationale of our experimental design is as follows: If, on the one hand, in the two agreement conditions, we find the same electrophysiological signals (ERPs) to violations in gender agreement regardless of the form of the noun, then our results indicate that, at least in the experiment carried out for the present study, the same neurocognitive processes in the processing of both regular and irregular gender forms are at work, which can be interpreted as evidence in favor of the single-mechanism view, since this view does not assume distinct neurocognitive processes for both types of word forms (Rodrigues-Fornells et al. 2001; Weyerts et al. 1997; Newman et al. 2007). If, on the other hand, in the two conditions, we find different electrophysiological signals indexing gender agreement with regular and irregular forms, then our data provides evidence that could support the dual route view of grammatical gender processing, which assumes a division of labour between rule-based and memory-based processes. Other than that, if we find differences in the electrophysiological patterns between the two agreement conditions, then our results suggest that the involvement of different word classes within the noun phrase agreement processing involves different neurocognitive processes.

As in our experiment we deal with morphosyntactic violations, we expect to find a biphasic LAN/P600 for violations in both conditions of agreement involving regular forms. Morphosyntactic violations are generally indexed by LANs (Barber and Carreiras 2005; Gunter et al. 2000; Hagoort 2003), a left anterior negativity component that typically appears between 
300 and $500 \mathrm{~ms}$ after stimulus onset and is believed to reflect automatic morphological structure building and procedural memory processes (Newman et al. 2007; Steinhauer and Connolly 2008; Ullman 2001, 2004). The late positivities (so-called P600) are ERP components that appear between 500 and $900 \mathrm{~ms}$ after stimulus onset usually associated with repair and re-analysis of (morpho)syntactic structures (Friederici et al. 2002).

The biphasic LAN/P600 effect is frequently reported in experiments that have manipulated noun phrase agreement (Barber and Carreiras 2005; Banón et al. 2012; Foucart and Frenck-Mestre 2012; Molinaro et al. 2008). However, LANs appeared in those experiments to violations in agreement involving regular forms, such as *a carro ("the DET FEM car NOUN MASC"). In contrast, late positivities seem to be sensitive to (morpho)syntactic violations but insensitive to word form differences since this component appears in a number of experiments dealing with morphosyntactic violations (Kaan and Swaab 2003; Osterhout and Holcomb 1992). Thus, in both gender agreement conditions, we predict to find only a P600 effect, not a biphasic LAN/P600 effect, to agreement violations involving irregular forms.

\section{Method}

\section{Participants}

Sixteen native speakers of Brazilian Portuguese (11 female), all students at the Radboud University (Nijmegen, The Netherlands) participated in the experiment. Age ranged from 20 to 41 years $($ mean $=28, S D=6.2$ ). Except for one, all participants were right-handed. As the EEG waves pattern of the left-handed participant did not differ from the pattern of all right-handed participants, we decided to keep the participant's data in the final analysis.

Participants reported no neurological or language impairments and had normal or corrected-to-normal vision. Participants signed a formal consent and received $€ 10$ (ten Euro) to participate in the experiment. Subjects stemmed from the participant pool of the Max Planck Institute for Psycholinguistics at Nijmegen and the experiment was carried out in accordance with the ethical requirements of the Institute. At the time of data collection, all subjects reported having lived less than 1 year in the Netherlands and using their mother tongue (Brazilian Portuguese) on a daily basis.

\section{Stimuli}

Stimuli set consisted of 256 different sentences divided into two conditions, each of which contains four stimuli categories. Table 1 displays the two conditions and the four categories of each condition.

Sentences were created with 128 nouns and 128 bigrams (nouns followed by adjectives) selected from the Corpus Brasileiro ${ }^{1}$ to be the critical words. Half of the nouns (64) were gender regular forms (feminine nouns ending in $-a$, and masculine nouns ending in $-o$ ) and the other half (64) were gender irregular forms (other endings). Half of the bigrams (64) were gender-regular bigrams (regular forms-feminine bigrams ending in - $a$, and masculine ending in - $o$ followed by adjectives allowing gender inflection) and the other half was composed of gender-irregular forms (other endings followed by adjectives allowing gender inflection). Table 2, displays the quantity of noun endings that composed the set of 128 gender irregular nouns selected for the experiment:

1 Available at linguateca: www.linguateca.pt. 
Table 1 Stimuli and categories

\begin{tabular}{|c|c|c|c|c|}
\hline & Critical word categories & $\begin{array}{l}\text { Quantity of } \\
\text { feminine nouns }\end{array}$ & $\begin{array}{l}\text { Quantity of } \\
\text { masculine nouns }\end{array}$ & $\begin{array}{l}\text { Total quantity } \\
\text { of nouns }\end{array}$ \\
\hline \multirow{2}{*}{$\begin{array}{l}\text { Incongruent } \\
\text { sentences } \\
\text { (condition 1) }\end{array}$} & Gender regular nouns $(-\mathrm{a},-\mathrm{o})$ & 15 & 17 & 32 \\
\hline & $\begin{array}{l}\text { Gender irregular nouns (other } \\
\text { endings) }\end{array}$ & 18 & 14 & 32 \\
\hline \multirow{2}{*}{$\begin{array}{l}\text { Incongruent } \\
\text { sentences } \\
\text { (condition 2) }\end{array}$} & Gender regular bigrams & 16 & 16 & 32 \\
\hline & Gender irregular bigrams & 16 & 16 & 32 \\
\hline \multirow{2}{*}{$\begin{array}{l}\text { Congruent } \\
\text { sentences } \\
\text { (condition 1) }\end{array}$} & Gender regular nouns $(-\mathrm{a},-\mathrm{o})$ & 16 & 16 & 32 \\
\hline & $\begin{array}{l}\text { Gender irregular nouns (other } \\
\text { endings) }\end{array}$ & 16 & 16 & 32 \\
\hline \multirow{2}{*}{$\begin{array}{l}\text { Congruent } \\
\text { sentences } \\
\text { (condition 2) }\end{array}$} & Gender regular bigrams & 16 & 16 & 32 \\
\hline & Gender irregular bigrams & 16 & 16 & 32 \\
\hline
\end{tabular}

Table 2 Gender irregular nouns: distribution of noun endings

\begin{tabular}{lllllllllll}
\hline $\begin{array}{l}\text { Word } \\
\text { endings }\end{array}$ & $\begin{array}{l}\text {-ão } \\
(\mathrm{fem})\end{array}$ & -ade & -agem & $\begin{array}{l}-\mathrm{a} \\
(\mathrm{masc})\end{array}$ & $-\mathrm{e}$ & $-\mathrm{m}$ & -1 & $-\mathrm{r}$ & $-\mathrm{s}$ & $-\mathrm{u}$ \\
\hline Example & questão & cidade & imagem & tema & noite & ordem & hotel & calor & onnibus & baú \\
Quantity & 24 & 19 & 9 & 7 & 41 & 1 & 10 & 11 & 4 & 2 \\
\hline
\end{tabular}

Gender regular and gender irregular nouns were matched by frequency $(\mathrm{t}=-1.70, \mathrm{df}=$ $125.74 p=0.09)$ as well as gender regular and gender irregular bigrams $(\mathrm{t}=-0.58, \mathrm{df}=$ $121.51, p=0.562$ ).

The set of stimuli was divided into gender agreement congruent and incongruent sentences. Hence, we obtained a total of 128 sentences with gender agreement incongruence between a determiner and a regular form (condition 1/32 sentences) or irregular form (condition 1/32 sentences) and between a regular form and an adjective (condition $2 / 32$ sentences) or an irregular form (condition 2/32 sentences) and an adjective. The other half (128) was composed of gender agreement congruent sentences between a determiner and a regular (condition 1/32 sentences) or irregular form (condition $1 / 32$ sentences) and a regular form and an adjective (condition 2/32 sentences) or irregular form and an adjective (condition 2/32 sentences). Examples of sentences in each condition and each category are displayed in Tables 3 and 4.

\section{Acceptability Test}

After creating all sentences, we submitted them to an acceptability test. The sentences included in this test were all grammatically congruent sentences, i.e., subjects did not judge sentences containing a grammatical gender violation. Consequently, for the acceptability 
Table 3 Stimuli examples of condition 1

\begin{tabular}{|c|c|c|}
\hline Condition 1 & Gender regular nouns & Gender irregular nouns \\
\hline Incongruent & $\begin{array}{l}\text { As fotos revelaram *o natureza do } \\
\text { caso } \\
\text { The photos showed } \\
\text { *the DET-MASC } \\
\text { nature NOUN FEM of the case }\end{array}$ & $\begin{array}{l}\text { Os atletas controlaram } \\
\text { *os fontes de energia } \\
\text { The athletes controlled } \\
\text { the DET MASC PL } \\
\text { sources NOUN FEM PL of energy. }\end{array}$ \\
\hline Congruent & $\begin{array}{l}\text { O paciente interrompeu o } \\
\text { tratamento de saúde } \\
\text { The pacient interrupted the } \\
\text { DET-MASC health } \\
\text { treatment }_{N O U N-M A S C}\end{array}$ & $\begin{array}{l}\text { Os trabalhadores receberam } \\
\text { aDET-FEM metade } \\
\text { das férias } \\
\text { Workers received the } \text { WET-FEM } \\
\text { half NOUN-FEM of the vacation } \\
\text { (payment) }\end{array}$ \\
\hline
\end{tabular}

Table 4 Stimuli examples of condition 2

\begin{tabular}{|c|c|c|}
\hline Condition 2 & Gender regular nouns & Gender irregular nouns \\
\hline Incongruent & $\begin{array}{l}\text { O documentário mostrou a } \\
\text { obra }_{N O U N-F E M} \\
\text { clássico ADJ-MASC do pintor } \\
\text { The documentary has shown } \\
\text { the } \text { DET-FEM classic ADJ-MASC }_{\text {work NOUN-FEM of the artist }}\end{array}$ & $\begin{array}{l}\text { O vapor representa a } \\
\text { * fase } \text { NOUN-FEM } \\
\text { gasoso } \text { ADJ-MASC da água. } \\
\text { Vapor is the } D E T-F E M \\
\text { gaseous } \\
\text { NODJ-MASC phase } \\
\text { NOUEM of the water }\end{array}$ \\
\hline Congruent & $\begin{array}{l}\text { A planilha informou o } \\
\text { lucro }{ }_{N O U N-M A S C} \\
\text { bruto } A D J-M A S C \text { do mês. } \\
\text { The spreadsheet informed } \\
\text { the } \text { DET-MASC gross }_{A D J-M A S C} \\
\text { profit }_{N O U N-M A S C} \text { of the month }\end{array}$ & $\begin{array}{l}\text { O técnico mudou o } \\
\text { esquema } \\
\text { tático } A D J-M A S C \text { do time. } \\
\text { The coach } \\
\text { has changed the } \text { DET-MASC tacti- }_{\text {- }} \\
\text { cal }_{A D J-M A S C} \text { scheme } \text { NOUN-MASC }_{\text {of }} \\
\text { of the team }\end{array}$ \\
\hline
\end{tabular}

test, sentences were divided into four conditions only, since we collapsed congruent and incongruent sentences of condition 1 and condition 2 (see Table 4).

The acceptability test was performed in two phases. In the first phase, five native speakers of Brazilian Portuguese judged the naturalness of the sentences. That is, they judged if, to them, the sentences sounded 'natural' or 'unnatural'. Speakers were required to provide better versions for the 'unnatural' sentences. Then, the altered versions (40 sentences) were included in the stimuli list. In the second phase, the new set of stimuli was submitted to fifteen native speakers of Brazilian Portuguese who were required to judge the naturalness of the sentences based on a seven point scale, with ' 1 ' indicating very strange and ' 7 ', very natural.

As none of the conditions obtained an average score below 5, all sentences were maintained in the final stimuli set. Table 5 displays the average score of acceptability test conditions.

Follow-up paired $t$-tests revealed that the distribution of scores for sentences containing gender regular did not differ statistically from the distribution of scores obtained for gender irregular forms, neither in condition $1(\mathrm{t}=1.4194, \mathrm{df}=627.26, p$ value $=0.15)$ nor in condition $2(\mathrm{t}=-0.29409, \mathrm{df}=637.7, p$ value $=0.076)$. We also ran a $2 \times 2$ repeated measures ANOVA within subjects and items having factor condition with two levels (condition 1 and condition 2) and factor form with two levels (regular and irregular forms). We did not find any statistically significant difference between factors condition and form (all corrected 
Table 5 Average scores of acceptability test per condition

\begin{tabular}{ll}
\hline Condition & Average score \\
\hline Condition 1: gender regular nouns & 6.37 \\
Condition 1: gender irregular nouns & 6.25 \\
Condition 2: gender regular nouns & 6.16 \\
Condition 2: gender irregular nouns & 6.19
\end{tabular}

\begin{tabular}{lll}
\hline Effect & $\mathrm{F}$ & $p$ value $>0.05$ \\
\hline Condition & $\mathrm{F}(1,4)=1.35$ & 0.3 \\
Form & $\mathrm{F}(1,4)=0.43$ & 0.54 \\
Condition: form & $\mathrm{F}(1,4)=1.38$ & 0.3 \\
\hline
\end{tabular}

Table 6 Results of repeated measures ANOVA for acceptability test

$p$ values $>0.05$ ). Table 6 displays the F-statistic from the repeated measures ANOVA and corrected $p$ values.

\section{Procedures}

After informed consent signature and cap set up, participants were conducted to a sound attenuated booth where the experiment took place. Procedures started with a brief practice session. Following the practice session, the main experimental stimuli list was presented.

Participants were instructed to read without blinking the sentences that appeared word-byword in the center of the screen. Each sentence began with a fixation sign that remained on the screen for $500 \mathrm{~ms}$. Words were presented for $200 \mathrm{~ms}$ with a length-dependent interword interval: $100 \mathrm{~ms}$ plus an additional $37 \mathrm{~ms}$ for each character in the word. A $2 \mathrm{~s}$ screen was introduced between sentences presentation with a sign allowing participants to blink.

The 256 sentences were presented in four blocks of 64 sentences. Each block contained eight sentences of each category of critical word (4 categories) in each condition of gender agreement (condition 1 and condition 2). Resting breaks were introduced inter blocks. Participants were advised that they were free to rest as long as they wished. The presentation of each block as well as sentences within each block were randomized across participants to avoid order effects. Six catch trials in the form of yes/no comprehension questions appeared in each block referring to a gender agreement congruent sentence for the control of participant's attention. The comprehension questions appeared immediately after presentation of the congruent sentence. To answer the questions, participants were instructed to press a green button for yes and red button for no.

It is important to clarify that because we controlled the nouns and bigrams selected by frequency, we could not adopt a Latin Square experimental design due to the reduced number of items obtained for each condition. Instead, we decided to create different sentences containing the items selected to avoid expectancy effects caused by the repetition of sentences.

\section{EEG Data Recording}

Electrical activity was recorded from 59 active electrodes referenced to the right mastoid. Vertical electroculogram (VEOG) was recorded by one electrode placed under the left eye. 


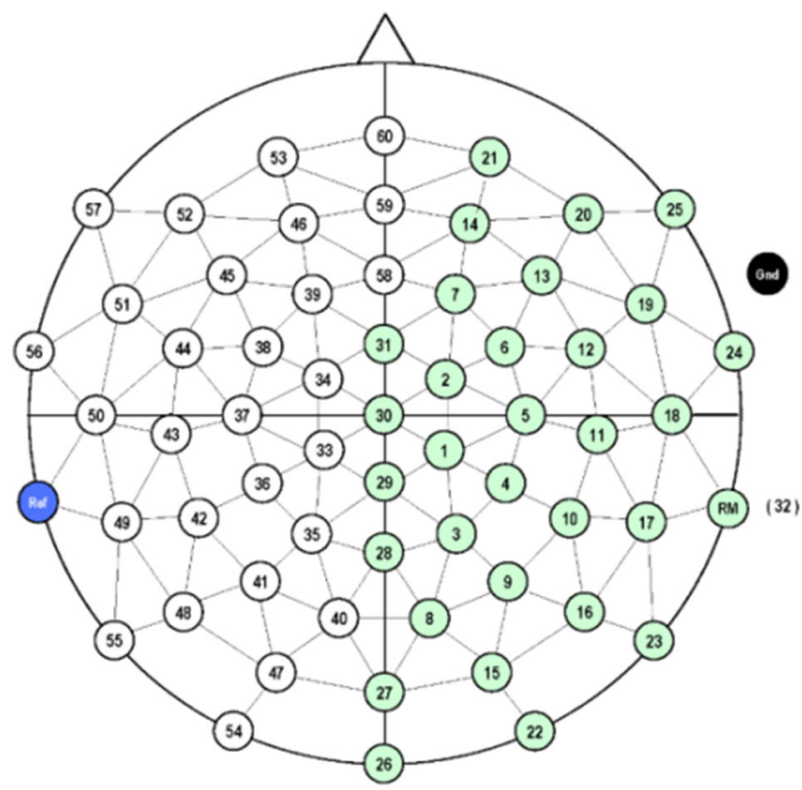

Fig. 1 Representation electrodes number selected per ROI. Channel nomenclature is by number

Horizontal electroculogram (HEOG) was recorded by two electrodes placed at the left and right outer canthus of the eyes. Impedance was kept below $5 \Omega$. EEG signals were digitized at $500 \mathrm{~Hz}$.

\section{Data Analysis}

Data analysis was carried out in Analyzer 2.0. All electrodes were re-referenced offline to the linked mastoid. EEG signals were averaged over epochs of $1200 \mathrm{~ms}$ including $200 \mathrm{~ms}$ prior to the stimulus onset for baseline correction. Before averaging, trials containing muscles artifacts and eye movements exceeding $\pm 100 \mu \mathrm{V}$ in amplitude were excluded. A low pass filter $(30 \mathrm{~Hz})$ and a high pass filter $(0.05 \mathrm{~Hz})$ were applied offline to the data.

For each participant, individual ERPs were averaged within each of the eight experimental conditions. ERP average amplitudes of the waveforms were computed for two specific time windows: between 300 and $500 \mathrm{~ms}$ to capture LANs and between 500 and $900 \mathrm{~ms}$ to capture late positivities.

Based on the visual inspection of the scalp distribution of the effects found, electrodes were selected (Fig. 1) in four regions of interest (ROIs) for the statistical analysis: left hemisphere frontal electrodes $(34,38,39,44,45,46,51,52,53,56,57)$; Midline $(26,27,28,29,30,31$, $58,59,60,37,50,5,18)$, left hemisphere posterior $(33,35,36 ; 40,41,42,43,47,48,49$, $54,55)$ and right hemisphere posterior electrodes $(1,3,4,8,9,10,11,15,16,17,22,23)$.

\section{Statistical Analysis}

We conducted a $2 \times 2 \times 2 \times 3 \times 2$ repeated measures analysis of variance (ANOVAs) with Condition (condition 1 vs. condition 2), Form (gender regular vs. gender irregular nouns), Hemisphere (left vs. right), Position (anterior, posterior, midline), Congruency (grammatical 
Gender agreement between determiner and gender regular nouns (ending in $-a$ and $-o$ )
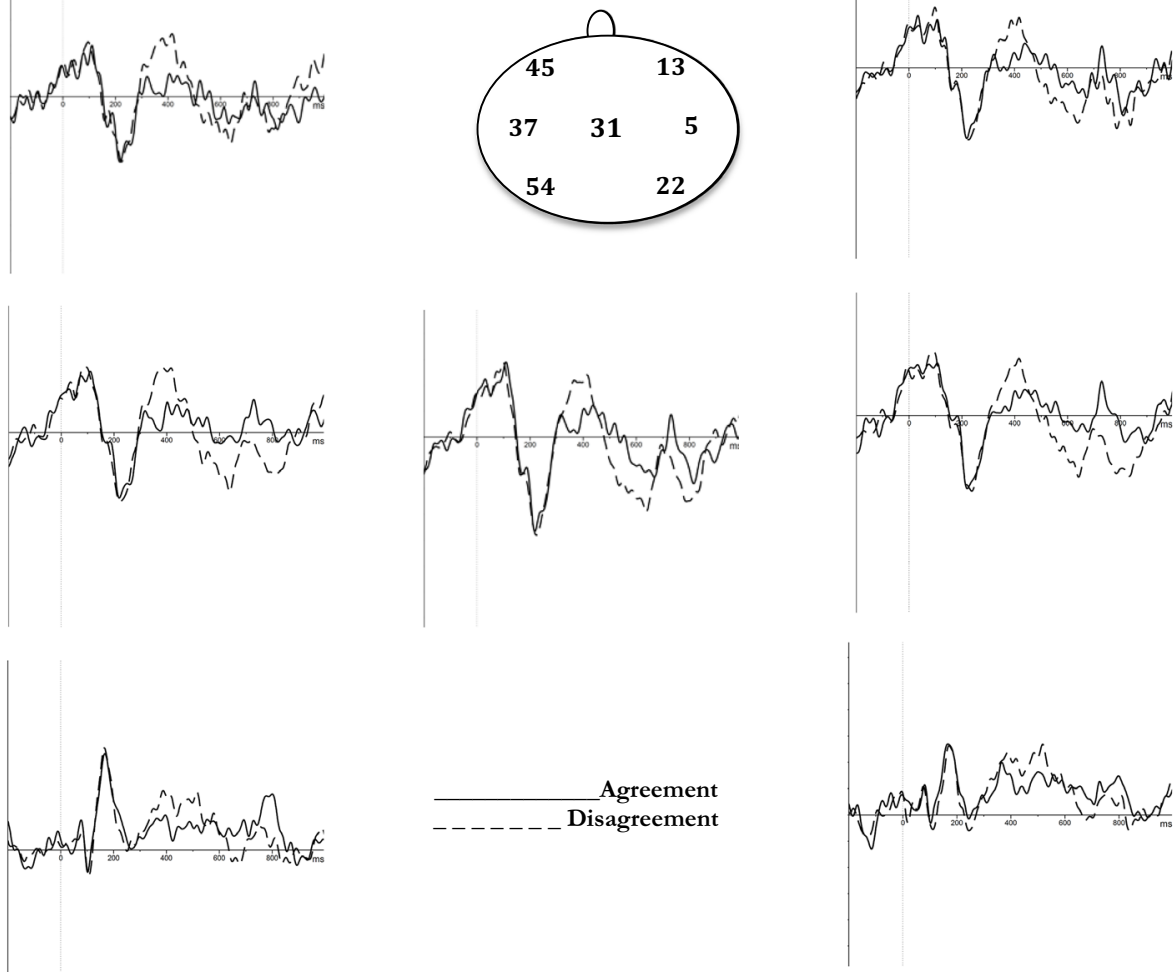

$300-500 \mathrm{~ms}$

$500-900 \mathrm{~ms}$
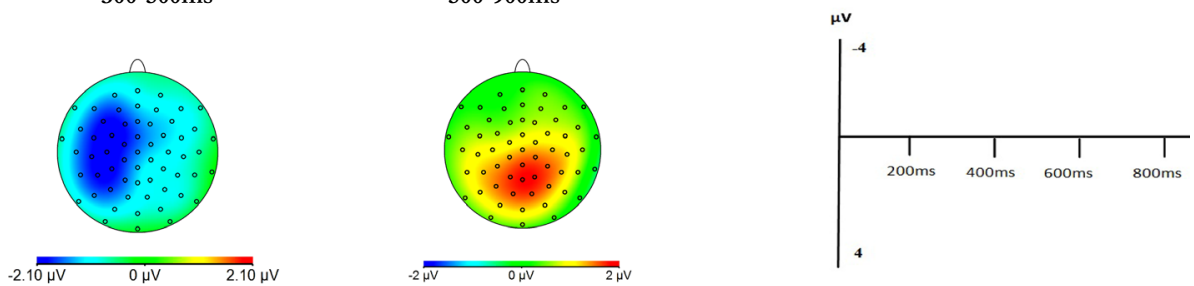

Fig. 2 Grand average waveforms of regular nouns in grammatical gender agreement and disagreement (condition 1)

gender congruent vs. incongruent sentences) as within-subject factors in the four ROIs separately with the aim to maximize statistical power. The Geisser and Greenhouse correction was applied to all repeated measures. We report here the original degrees of freedom and the corrected p-values.

\section{Results}

Figures 2 and 3 display grand average ERP waveforms of gender agreement congruent and incongruent sentences between a determiner and a noun (condition 1). Trials were time locked 
Gender agreement between determiner and gender irregular nouns (other endings)
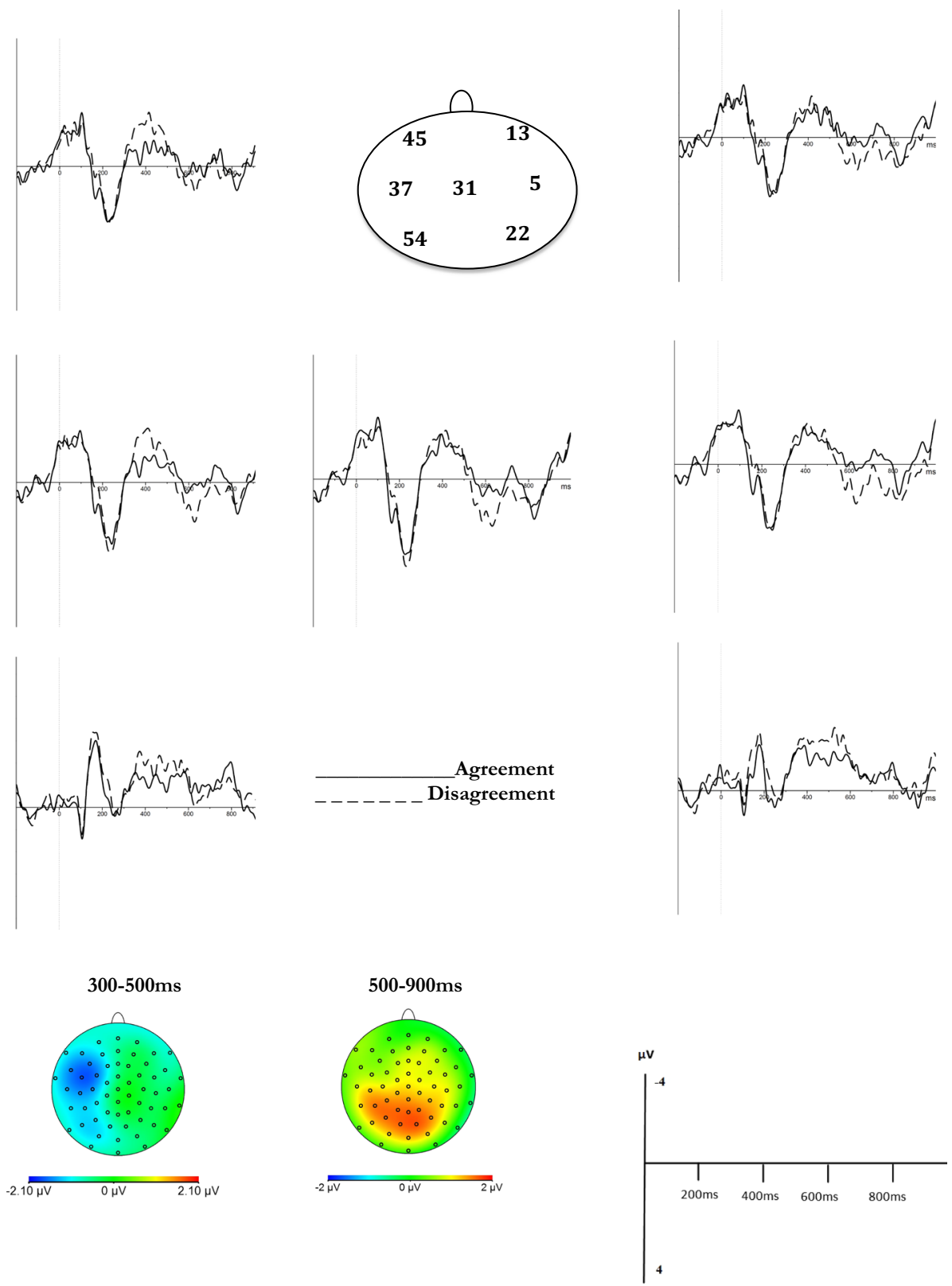

Fig. 3 Grand average waveforms of irregular nouns in grammatical gender agreement and disagreement (condition 1)

to the onset of the regular and irregular nouns following the determiner. Visual inspection of Fig. 2 suggests difference between grammatical gender congruent and incongruent sentences, but no difference in peak amplitude between regular and irregular nouns in left hemisphere 
Gender agreement between adjectives and gender regular nouns (endings in -a an -o)
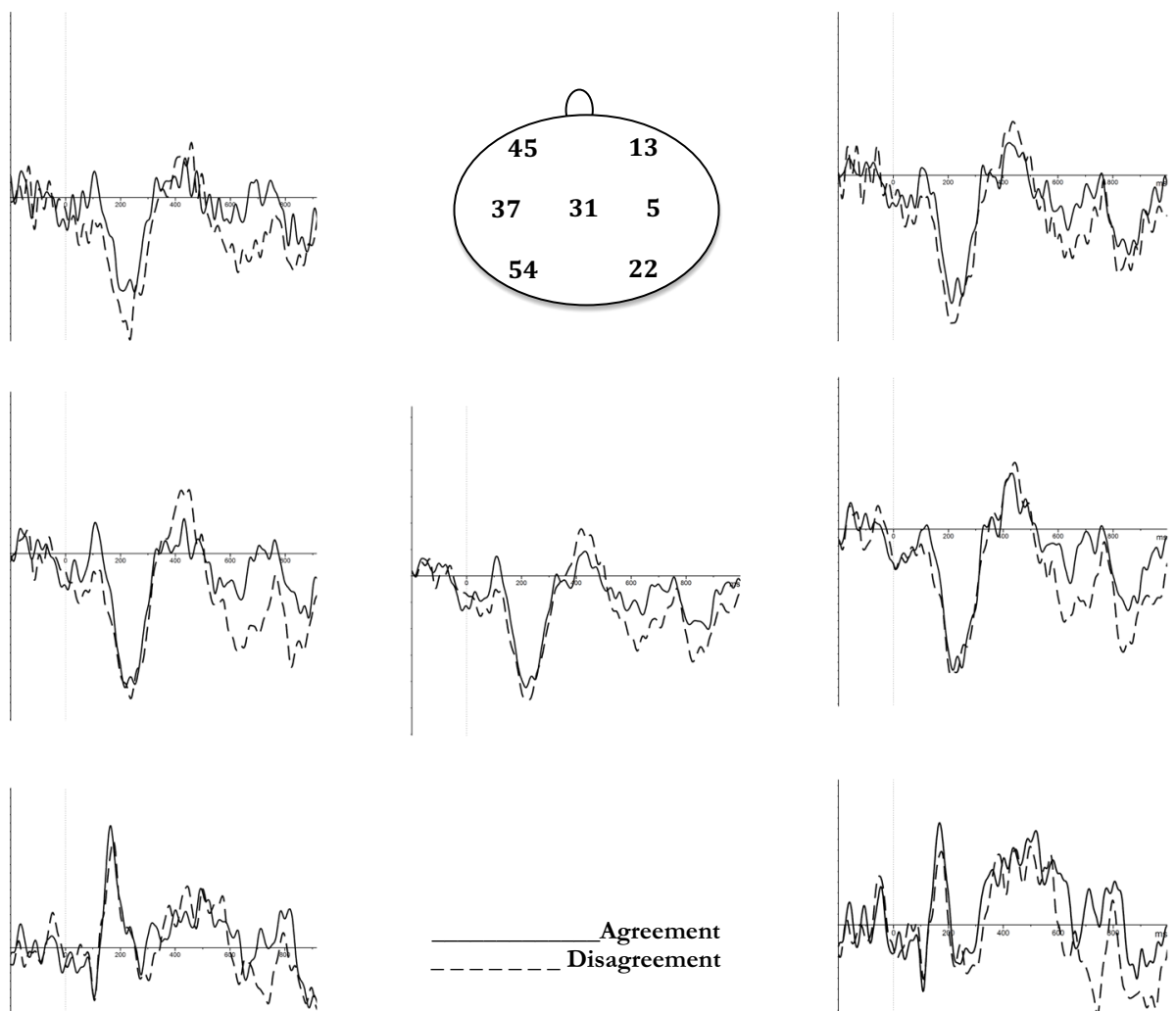

Agreement
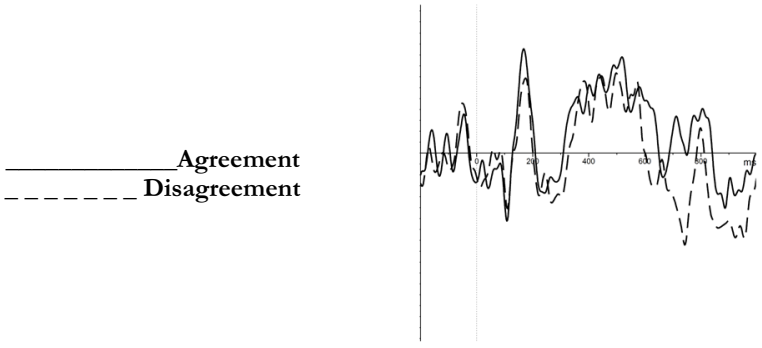

$300-500 \mathrm{~ms}$

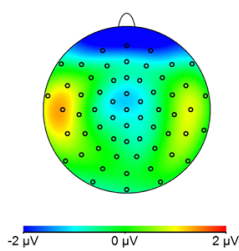

$500-900 \mathrm{~ms}$

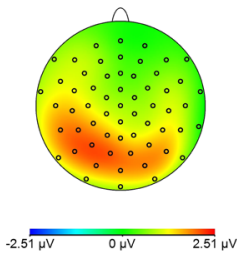

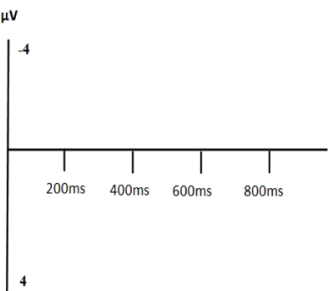

Fig. 4 Grand average waveforms of regular nouns in grammatical gender agreement and disagreement (condition 2)

(anterior, posterior and midline positions) in both the $300-500 \mathrm{~ms}$ and $500-900 \mathrm{~ms}$ time windows.

Figures 4 and 5 display grand average ERP waveforms of gender agreement congruent and incongruent sentences between a noun and an adjective (condition 2). Trials were time 

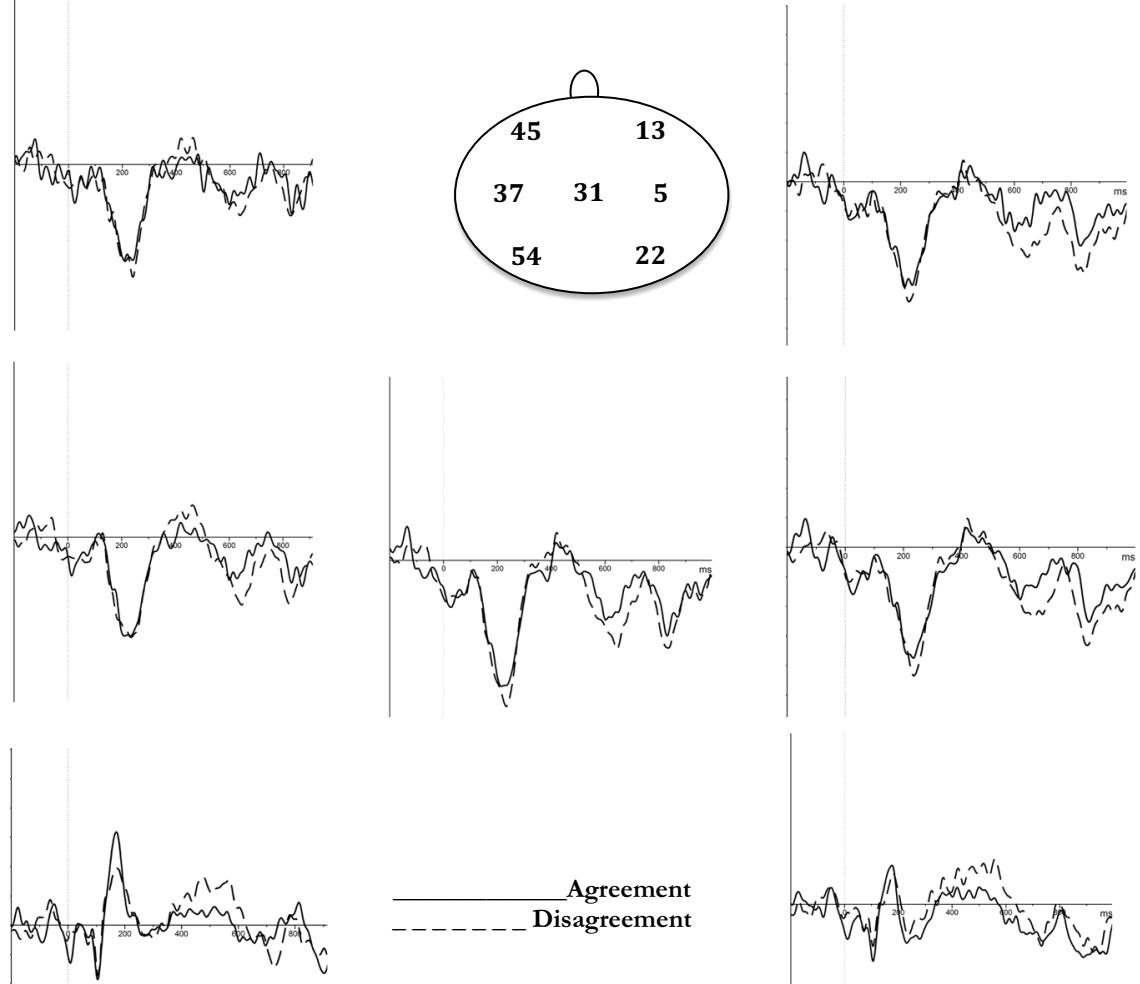

Agreement
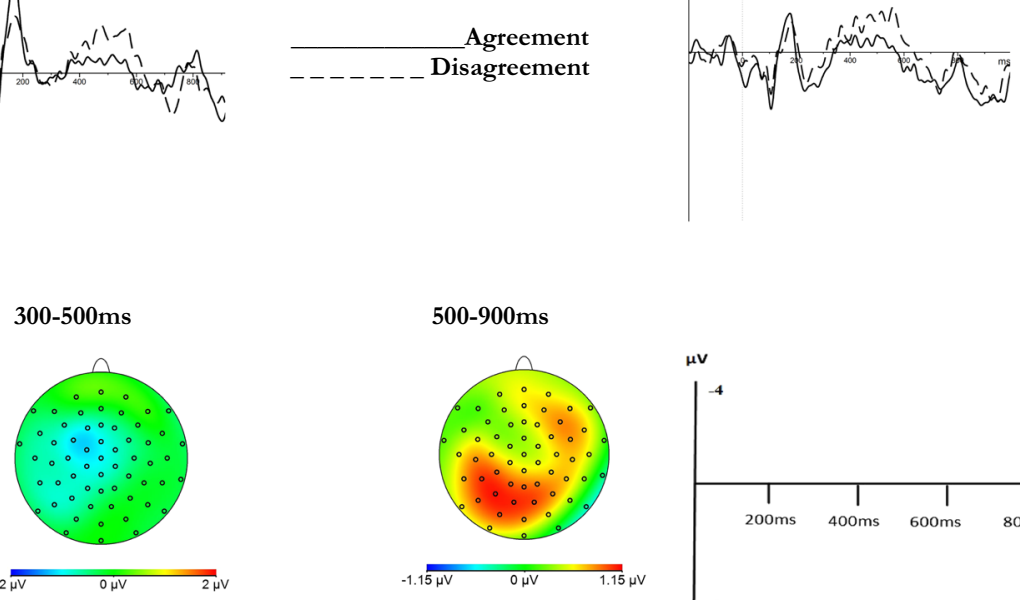

$500-900 \mathrm{~ms}$

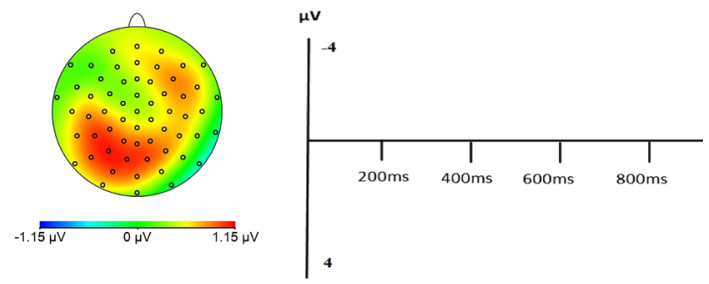

Fig. 5 Grand average waveforms of irregular nouns in grammatical gender agreement and disagreement (condition 2)

locked to the onset of the grammatical gender congruent and incongruent adjective following regular and irregular nouns. Visual inspection of Figs. 4 and 5 suggests differences between grammatical gender congruent and incongruent sentences but no difference between regular and irregular nouns in left hemisphere (anterior, posterior) in the 300-500 ms time window.

As regards the 500-900 ms time window, visual inspection of waveforms in Figs. 2, 3, 4, and 5 suggests differences between grammatical gender congruent and incongruent sentences 
and no significant differences between regular and irregular nouns in left hemisphere (anterior, posterior and midline positions) in both agreement conditions. In both agreement conditions, incongruent sentences involving regular and irregular nouns elicited more negative going waveforms than congruent sentences.

In the 300-500 ms time window, scalp distribution of ERPs (Figs. 2, 3) suggests a LAN (left anterior negativity) for trials with regular and irregular nouns both in condition 1 and condition 2. Statistically, this effect was revealed by the ANOVA as a significant independent effect of the factor Congruency in the anterior position of the left anterior hemisphere $(\mathrm{F}(1,15)=4.75, p=0.04)$ only. That is, no other effects were found in this time window.

In the 500-900 ms time window, scalp distribution of the ERPs (Figs. 2, 3, 4, 5) suggests a posterior P600 for trials with regular and irregular nouns in condition 1 and condition 2. However, in condition 2, trials with incongruent regular forms elicited more positive ongoing waveforms than trial with incongruent irregular sentences. Statistically, this was revealed by the ANOVA as a main effect of factors Condition $(\mathrm{F}(1,15)=4.59, p<0.05)$, Congruency $(\mathrm{F}(1,15)=7.4, p<0.01)$ and a two way interaction between factors Congruency and Form $(\mathrm{F}(1,15)=7.5, p<0.01)$.

Figures 2, 3, 4, 5 show voltage topographic maps obtained by the difference waves (incongruent minus congruent sentences) from 59 sites for the 300-500 ms and 500-900 ms time windows.

\section{Discussion}

In the present paper, we report a study that aimed at investigating the routes of grammatical gender processing in Brazilian Portuguese involving inanimate nouns. Specifically, we investigated if gender agreement processing of gender regular forms (feminine nouns ending in -a and masculine nouns ending in -o) and gender irregular forms (feminine and masculine nouns with endings different from $-a$ and $-o$ ) activate the same or different neurocognitive mechanisms/routes. Due to cross-linguistic controversial results, we adopted an electrophysiological approach as an attempt to disentangle issues raised by studies based on data from behavioral experimental paradigms.

In our experimental design, subjects were presented with 256 sentences divided into eight conditions (32 trials per condition), namely: congruent and incongruent grammatical gender agreement between a determiner and a regular or an irregular form (condition 1); congruent and incongruent grammatical gender agreement between a regular or an irregular form and an adjective (condition 2). We compared the ERP signals elicited by grammatical gender agreement with either a regular or an irregular form during a sentence comprehension task in the two gender agreement conditions.

The most important finding in our experiment is that both regular and irregular forms elicited a biphasic LAN/P600 in both conditions. The LAN component elicited by gender regular and irregular shows that both forms can activate the same neurocognitive mechanisms. Further, these results also suggest that the activation of mechanisms associated with automatic, procedural processing is independent of the form of the noun.

As regards the 500-900 ms time window, we observed a statistically significant independent effect of factors Congruency and Condition, and a two-way interaction between factors Congruency and Form, revealing that there is a difference between conditions and the ERPs elicited by regular and irregular nouns and regular and irregular bigrams differ. In condition two, incongruent regular forms elicited more positive waveforms as compared to 
incongruent irregular forms. We interpret these results as differences in repair and reanalysis due to structural differences between condition 1 and condition 2. This difference might be due to the fact that, while in condition 1 the gender of the determiners triggers an expectation for nouns with the same gender, in condition 2, the gender of the nouns does not trigger such expectation for the input of adjectives. Thus, it is possible that the violation of such expectation elicits a difference in reanalysis effect between conditions.

As suggested by visual inspection of Figs. 4 and 5 and the two-way interaction between factors Congruency and Form, there is a difference in peak amplitude between regular and irregulars in condition 2. This result suggests that, both regular and irregular nouns activate neurocognitive mechanisms associated with repair and reanalysis. Nevertheless, it seems that a gender agreement violation between gender regular nouns and adjectives is more readily detected than the violation between gender irregular nouns and adjectives, possibly due to differences in the frequency of the pattern of agreement between a regular noun and an adjective, on the one hand, and an irregular noun and an adjective, on the other hand. For instance, it could be that a violation in the agreement in roup-a bonit-a ("nice" Fem "clothes" Fem) is more easily detected than a violation in the agreement noit-e estrelad- $a$ ("starry"Fem "night" Fem) because in Portuguese the regular pattern feminine nouns ending in $-a$ and masculine nouns ending in $-o$ is far more frequent than feminine nouns ending in $-e$ or other endings.

What are the implications of our results for models of morphological and gender processing? First of all, contrary to the hypotheses raised by dual models of morphological processing (see Marslen-Wilson 2007; Pinker 1991, 1998; Ullman 2001), to the results of previous studies on the processing of regular and irregular morphology, and to the hypothesis of dual route for grammatical gender processing (Caffarra et al. 2015; Gollan and Frost 2001), the results of the present study indicate that regular and irregular grammatical gender processing in Portuguese seems to depend on a single neurocognitive mechanism. These results are in conflict with studies (e.g., Hernandez et al. 2007; Rodrigues-Fornells et al. 2001; Newman et al. 2007) that show a qualitative difference between opaque and regular/transparent forms. Our findings seem to be in line with Bybee's Network Model (1995) of morphological processing which assumes that differences in processing costs between morphologically complex and simplex forms are not associated with distinct (neuro)cognitive mechanisms, but with differences in the frequency of occurrence of a pattern.

In sum, the results of the present study replicate previous findings concerning gender agreement violations (e.g. Barber and Carreiras 2005; Molinaro et al. 2008). We found a biphasic LAN/P600 typical of local morphosyntactic violations. Contrary to behavioral studies for other languages suggesting that gender irregular word forms are retrieved from memory and gender regular word forms are computed on the fly, in the study for Portuguese reported here, we did not find evidence to support this claim. In fact, the results of the present study indicate that violations with irregular nouns can elicit a LAN. Thus, our data do not confirm our previous hypothesis that a biphasic LAN would be elicited only by gender regular nouns. Our findings are in line with models of morphological processing that assume shared neurocognitive mechanisms for gender regular and gender irregular forms.

Acknowledgements We are grateful to Daniel Acheson, for his valuable support in the analysis of data, and to Peter Hagoort, for generously granting access to equipment and resources at the Max Planck Institute for Psycholinguistics, Nijmegen.

Funding This study was funded by CAPES (Program CAPES/NUFFIC Project 051/13 -Grant Number 23038.007129/2013-40, awarded to Mailce Borges Mota, and Program CAPES Doutorado SWE Grant Number 115981/13-1, awarded to Natália Carolina Alencar de Resende. 


\section{Compliance with Ethical Standards}

Conflict of interest The authors declare that they have no conflict of interest.

\section{References}

Afonso, O., Domínguez, A., Álvarez, C. J., \& Morales, D. (2014). Sublexical and lexico-syntactic factors in gender access in Spanish. Journal of Psycholinguistic Research, 43, 13-25.

Banón, J. A., Fiorentino, R., \& Grabriele, A. (2012). The processing of number and gender agreement in Spanish: An event-related potential investigation of the effects of structural distance. Brain Research, 1456, 49-63.

Barber, H., \& Carreiras, M. (2005). Gramatical gender and number agreement in Spanish: An ERP comparison. Journal of Cognitive Neuroscience, 17(1), 137-153.

Barber, H., Salillas, E., \& Carreiras, M. (2004). Gender or genders agreement? In M. Carreiras \& C. Clifton (Eds.), On-line study of sentence comprehension: eyetracking, ERP and beyond (pp. 309-328). London: Psychology Press.

Bates, E. A., \& Devescovi, A. (1989). Crosslinguistic studies of sentence production. In B. MacWhinney \& E. A. Bates (Eds.), The crosslinguistics study of sentence processing (pp. 225-253). Cambridge: Cambridge University Press.

Bates, E., Devescovi, A., Hernandez, A., \& Pizzaniglio, L. (1996). Gender priming in Italian. Perception and Psychophysics, 58, 992-1004.

Bates, E., Devescovi, A., Pizzamiglio, L., D’Amico, S., \& Hernandes, A. (1995). Gender and lexical access in Italian. Perception and Psychophysics, 57, 847-862.

Bybee, J. L. (1995). Regular morphology and the lexicon. Language and Cognitive Processes, 10, 425-455.

Caffarra, S., Syianova-Chanturia, A., Pesciarelli, F., Vespignani, F., \& Cacciari, C. (2015). Is the noun ending a cue to grammatical gender processing? An ERP study on sentences in Italian. Psychophysiology, 52(8), 1019-1030.

Clark, E. (1985). The acquisition of romance with special reference to French. In D. Slobin (Ed.), The crosslinguistic study oflanguage acquisition. The data (Vol. 1, pp. 687-782). Hillsdale, NJ: Lawrence Erlbaum.

Corbett, G. G. (1991). Gender. Cambridge: Cambridge University Press.

Corrêa, L., \& Name, M. C. (2003). The processing of determiner-noun agreement and the identification of the gender of nouns in the early acquisition of Portuguese. Journal of Portuguese Linguistics, 2, 19-43.

Desrochers, A., Paivio, A., \& Desrochers, S. (1989). L'effet de la frequence d'usage des noms inanimes et de la valeur predictive de leur terminaison sur 1'identification du genre gramatical. Revue Canadienne de Psychologie, 43, 62-73.

Dominguez, A., Cuetos, F., \& Segui, J. (1999). The processing of grammatical gender and number in Spanish. Journal of Psycholinguistic Research, 28(5), 485-497.

Foucart, A., \& Frenck-Mestre, C. (2012). Can late L2 learners acquire new gramatical features? Evidence from ERPs and eye-tracking. Journal of Memory and Language, 66, 226-248.

Friederici, A. D., Hahne, A., \& Saddy, D. (2002). Distinct neurophysiological patterns reflecting aspects of syntactic complexity and syntactic repair. Journal of Psycholinguistic Research, 31(1), 45-63.

Gollan, T., \& Frost, R. (2001). Two routes to gramatical gender: Evidence from Hebrew. Journal of Psycolinguistic Research, 30(6), 627-651.

Gunter, T. C., Friederici, A. D., \& Schriefers, H. (2000). Syntactic gender and semantic expectancy: ERPs reveal early autonomy and late interaction. Journal of Cognitive Neuroscience, 12(4), 556-568.

Hagoort, P. (2003). How the brain solves the binding problem for language: a neurocomputational model of syntactic processing. Neuroimage, 20, 18-29.

Hernandez, A. E., Hofmann, J., \& Kotz, S. A. (2007). Age of acquisition modulates neural activity for both regular and irregular syntactic functions. NeuroImage, 36, 912-923.

Hernandez, A. E., Kortz, A. S., Hofmann, J., Valentin, V. V., Dapretto, M., \& Bookheimer, S. (2004). The neural correlates of grammatical gender decisions in Spanish. NeuroReport, 15(5), 863-866.

Hohfeld, A. (2006). Accessing gramatical gender in german: The impact of gender-marking regularities. Applied Psycholinguistics, 27, 127-142.

Jensen, J. B. (1989). On the mutual intelligibility of Spanish and Portuguese. Hispania, 72, 848-852.

Jescheniak, J. D., \& Levelt, W. J. M. (1994). Word frequency effects in speech production: Retrieval of syntactic information and of phonological form. Journal of Experimental Psychology: Learning, Memory, and Cognition, 20(4), 824-843. https://doi.org/10.1037/0278-7393.20.4.824. 
Kaan, E., \& Swaab, T. (2003). Repair, revision, and complexity in syntactic analysis: An electrophysiological differentiation. Journal of Cognitive Neuroscience, 15, 98-110.

Levelt, W. J. M., Roelofs, A., \& Meyer, A. S. (1999). A theory of lexical access in speech production. Behavioral and Brain Sciences, 22, 1-75.

Marslen-Wilson, W. D. (2007). Morphological processes in language comprehension. In G. Gaskell (Ed.), Oxford handbook of psycholinguistics (pp. 175-193). Oxford: Oxford University Press.

Matthews, C. (2010). On the nature of phonological cues in the acquisition of French gender categories: Evidence from instance-based learning models. Lingua, 120(4), 879-900.

Molinaro, N., Barber, H. A., \& Carreiras, M. (2011). Grammatical agreement processing in reading: ERP findings and future directions. Cortex, 47, 908-930.

Molinaro, N., Kim, A., Vespignani, F., \& Job, R. (2008). Anaphoric agreement violation: An ERP analysis of its interpretation. Cognition, 106(2), 963-974.

Newman, A. J., Ullman, M. T., Pancheva, R., Waligura, D. L., \& Neville, H. J. (2007). An ERP study of regular and irregular English past tense inflection. NeuroImage, 34, 435-445.

Osterhout, L., \& Holcomb, P. J. (1992). Event-related brain potentials elicited by syntactic anomaly. Journal of Memory and Language, 31, 785-806.

Padovanni, R., Calandra-Buonaura, G., Cacciari, C., Benuzzi, F., \& Nichelli, P. (2005). Gramatical gender in the brain: Evidence from an fMRI study on Italian. Brain Research Bulletin, 65, 301-308.

Pérez Pereira, M. (1991). The acquisition of gender: What Spanish children tell us. Journal of Child Language, 18, 571-590.

Pinker, S. (1991). Rules of language. Science, 253, 530-535.

Pinker, S. (1998). Words and rules. Lingua, 106, 219-242.

Rodina, Y. (2007). What do asymmetries in children's performance tell us about the nature of their underlying knowledge? Nordlyd, 34, 230-251.

Rodriguez-Fornells, A., Clahsen, H., Lleo, C., Zaake, W., \& Muente, T. F. (2001). Event_related brain responses to morphological violations in Catalan. Cognitive Brain Research, 11, 47-58.

Roelofs, A. (1992). A spreading-activation theory of lemma retrieval in speaking. Cognition, 42, $107-142$.

Seigneuric, A., Zagar, D., Meunier, F., \& Spinelli, E. (2007). The relation between language and cognition in 3- to 9-year-olds: The acquisition of grammatical gender in French. Journal of Experimental Child Psychology, 96, 219-246.

Steinhauer, K., \& Connolly, J. (2008). Event-related potentials in the study of language. In B. Stemmer \& H. A. Whitaker (Eds.), Handbook of neuroscience of language (pp. 91-104). San Diego, CA: Academic Press.

Taft, M., \& Meunier, F. (1998). Lexical representation of gender: A quasiregular domain. Journal of Psycholinguistic Research, 27(1), 23-45.

Tucker, G. R., Lambert, W. E., Rigault, A. A., \& Segalowitz, N. (1968). A psychological investigation of French speaker's skill with gramatical gender. Journal of Verbal Learning and Verbal Behavior, 7, 312-316.

Ullman, M. T. (2001). The declarative/procedural model of lexicon and grammar. Journal of Psycholinguistic Research, 30(1), 37-69.

Ullman, M. T. (2004). Contributions of memory circuits to language: The declarative/procedural model. Cognition, 92(1-2), 231-270.

Weyerts, H., Penke, M., Dohrn, U., Clahsen, H., \& Munte, T. F. (1997). Brain potentials indicate differences between regular and irregular German plurals. NeuroReport, 8, 957-962. 